\title{
Conflicto armado y legislaciones penales especiales
}

JORGE ENRIQUE CARVAJAL MARTÍNEZ*

\section{RESUMEN}

En una situación de conflicto armado, los Estados desarrollan legislaciones penales especiales. En ellas, se establecen procedimientos, sanciones y condenas, y se dan mayores prerrogativas a las Fuerzas Armadas con el fin de limitar el accionar de los grupos armados que se enfrentan al Estado. Sin embargo, las medidas de excepción afectan a la población civil y, por este motivo, son permanentemente cuestionadas por organismos internacionales. El objetivo del presente artículo es establecer las características de los actuales conflictos armados y señalar los límites de las legislaciones especiales y el papel del poder judicial para evitar la arbitrariedad del poder ejecutivo, tomando algunos elementos del caso colombiano, único país de la región que presenta un conflicto armado interno aún sin resolver.

\section{PALABRAS CLAVE}

Conflicto armado, guerra, legislaciones especiales, derecho internacional, castigo, independencia judicial.

\section{ABSTRACT}

In a situation of Armed Warfare the States develop special Criminal laws, within them are established Procedures, Punishments and Sentences and are given more prerogatives to the Armed Forces with the purpose of limit the activity of the insurgent groups that confront the States. Nevertheless the exceptional measures affect to the civil population and that is the reason why that measures are

\footnotetext{
Abogado; Licenciado en Ciencias Sociales, Especializado en Sociología Jurídica; Maestría en curso de Ciencias Políticas y Relaciones Internacionales; Profesor de la Facultad de Derecho, Universidad Santo Tomás.
} 
constantly criticized by the International organisms. The object of this Article is to try to establish the characteristics of the present armed warfares and point out the limits of the special Legislations and the role of the Judiciary to avoid the arbitrariness of the Executive, taking some elements from the Colombian case, the only Country of the Region that have an internal Armed warfare without a solution yet.

\section{INDEX TERMS}

Armed warfare, war, special criminal laws, international law, punishment, judiciary independence.

\section{INTRODUCCIÓN}

Colombia, como la mayoría de los países de la región de América Latina y el Caribe, atraviesa por una serie de transformaciones en el campo económico, social y político. En lo político, la última década del siglo XX se caracterizó por un fortalecimiento de las instituciones democráticas. De forma paralela, se implementó en lo económico el modelo neoliberal, que ha generado mayor exclusión social y empobrecimiento de importantes sectores de la sociedad. Sin embargo, Colombia tiene una particularidad adicional: actualmente es el único país de la región que posee un conflicto armado interno aún sin resolver.

Como consecuencia de ello, el país vive una tensión permanente entre democracia y guerra que afecta a la sociedad en su conjunto. Nos interesa establecer, por lo tanto, en este artículo, los límites del Estado en un contexto de conflicto armado. Para este propósito, hemos dividido nuestra reflexión en tres partes. En primer lugar, se analizarán las características propias de los conflictos armados; en segundo lugar, se presentarán las restricciones que para evitar la arbitrariedad del Estado en un contexto de confrontación interna señalan los organismos internacionales; en tercer lugar, se analiza el papel de la administración de justicia. Por último, se aborda el caso colombiano desde la perspectiva de la Constitución de 1991.

\section{EL CONFLICTO ARMADO}

En contextos de guerra, los Estados desarrollan legislaciones penales especiales que tienen como principal justificación dotar a las instituciones encargadas de la defensa del Estado de herramientas que le permitan ampliar su estrategia de guerra amparadas en un marco legal.

Las adecuaciones legislativas en tiempos de guerra generan innumerables debates, la mayoría orientados a establecer si son o no necesarias, su grado de validez y eficacia y las implicaciones para los Derechos Humanos y el Derecho Internacional Humanitario. Sin embargo, el ejercicio de la guerra genera efectos que van más allá de los efectos sociales. El conflicto puede ayudar a consolidar la formación de los Estados y de sus instituciones (Tilly, 1990: 40). Algunas veces, la guerra acompaña a la consolidación de los regímenes de democráticos (Wills, 1998: 16) y, por último, la guerra puede ocasionar el exterminio de otras culturas.

A través de la historia hemos presenciado diversas formas de hacer la guerra. En la modernidad se han presentado cuatro modelos de procesos violentos: la guerra clásica o entre Estados, la guerra entre bloques ideológicos o "guerra fría", la guerra interna y, más recientemente, la denominada guerra contra el terrorismo. En cada uno de estos escenarios, la guerra se sustenta por medio de formas narrativas o discursivas, se ajus- 
tan reglas o normas para regular la guerra, se centraliza y aumenta el poder Estatal y se establecen numerosos tributos para pagar los costos que los actos violentos demandan.

En la guerra clásica, el objetivo fundamental era el control de territorios y recursos. Por esta razón, la ocupación del territorio del enemigo por parte del ejército de uno de los Estados era la característica principal. La población civil no era objetivo militar directamente. Por medio del derecho de gentes se establecieron reglas que señalaban los límites de los ejércitos y el trato que éstos debían dar a su rival, posteriormente se establecieron en el Derecho Internacional Humanitario ${ }^{1}$ regulaciones sistemáticas sobre el conflicto armado.

La "Guerra Fría", por su parte, implicó el enfrentamiento de dos superpotencias (Estados Unidos y la URSS). La confrontación entre las dos involucró al mundo entero, como consecuencia de su pretensión de imponer, a escala global, su modelo económico, político y social. En ese enfrentamiento, la carrera armamentista y la amenaza nuclear fueron ingredientes de disuasión entre las dos superpotencias (Hobsbawm, 1997, Howard y W. Roger, 1999). El Derecho Internacional producido por las Naciones Unidas jugó un papel distensivo durante en esta etapa. Aunque este tipo de confrontación no exigía control directo territorial de parte de las superpotencias enfrentadas, sí exigía la instauración de gobiernos "amigos" o leales a una u otra, para lo cual apoyaban insurrecciones internas, guerra de guerrillas o incluso guerras civiles para lograr dicho propósito.
Con el final de la Guerra Fría, aparece un nuevo tipo de guerra o de violencia organizada que Ilamaremos la guerra de la globalización. Éste es tipo de guerra complejo, ya que conjuga nuevos actores y diversos intereses políticos. "Las nuevas guerras implican un desdibujamiento de las distinciones entre guerra (normalmente definida como violencia por motivos políticos entre Estados o grupos políticos organizados), crimen organizado (la violencia por motivos particulares, en general el beneficio económico, ejercida por grupos organizados privados) y violaciones a gran escala de los Derechos Humanos (la violencia contra personas individuales ejercida por Estados o grupos organizados políticamente)"(Kaldor, 2001:16).

Las nuevas guerras, en su mayoría, son de carácter local, calificadas como guerras civiles o internas. A pesar de esta característica, los conflictos internos transcienden los espacios locales e involucran espacios regionales y, en algunos casos, adquieren relevancia global. Son muchos los elementos que dan a las nuevas guerras el carácter de globalización: los medios de comunicación, el tráfico internacional de armas, los asesores militares extranjeros, las intervenciones de organizaciones no gubernamentales y de la ONU, actores todos que en definitiva le dan carácter global a una situación de conflicto interno.

Otra característica de las nuevas guerras es que reflejan el debilitamiento del Estado moderno, bien sea porque éste pierde autonomía o porque sufre síntomas de desintegración. Muchos de los Estados de la posguerra fría han perdido el monopolio legítimo de la fuerza.

\footnotetext{
la1 Sobre el tema, ver: “Convenio de Ginebra para aliviar la suerte que corren los heridos, los enfermos y los náufragos de las fuerzas armadas en el mar (Convenio II). Convenio de Ginebra relativo al trato debido a los prisioneros de guerra (Convenio III) y el Convenio de Ginebra relativo a la protección debida a las personas civiles en tiempo de guerra (Convenio IV). Estos fueron aprobados el 12 de agosto de 1949 por la Conferencia Diplomática para Elaborar Convenios Internacionales Destinados a Proteger a las Víctimas de la Guerra, celebrada en Ginebra del 12 de abril al 12 de agosto de 1949.
} 
Las guerras de la actualidad se han privatizado:

"la violencia está cada vez más privatizada, como consecuencia del creciente crimen organizado y la aparición de grupos paramilitares, mientras la legitimidad política va desapareciendo. Por lo tanto, las distinciones entre barbarie externa y el civismo interno, entre el combatiente como legítimo portador de armas y el no combatiente, el soldado o policía y el criminal, son distinciones que están desvaneciéndose" (Kaldor, 2001: 20).

La Guerra Interna en Colombia no necesariamente contiene todos los elementos que señala Kaldor en su análisis de las nuevas guerras. Una singularidad del conflicto armado interno es su carácter prolongado, la presencia continuada de la guerrilla de izquierda con más de cuatro décadas de accionar y la aparición, en los años 80, de grupos paramilitares como nuevo actor del conflicto armado.

\section{EL CONFLICTO: COERCIÓN Y CASTIGO}

En la guerra, la amenaza o el uso de la fuerza es un recurso común a los diferentes tipos de violencia. La coerción "incluye toda aplicación concertada, como amenaza o como realidad, de acciones que por lo general causan pérdida o perjuicio a las personas o a las posesiones de particulares o grupos, los cuales son conscientes tanto de la acción como de los posibles daños" (Tilly, 1990:44).

En un conflicto interno, los Estados buscan restablecer el monopolio de la fuerza legítima dentro de su territorio. Sin embargo, el monopolio legítimo de la fuerza no se ejerce únicamente por medio de la Fuerza Armada, sino que existen instituciones que ejercen o aplican la coerción, como la policía, el sistema penitenciario, el derecho penal y las legislaciones especiales. En un Estado involucrado en una guerra interna, todas las instituciones tienden a ejercer y legitimar la fuerza. De la misma manera, es inevitable la vinculación de los gobernados al conflicto.

"La preparación de la guerra, especialmente a gran escala, involucra a sus gobernantes, inevitablemente, en la extracción. Con ello, se crea una infraestructura de tributación, abastecimiento y administración que exige su propio mantenimiento y que, a menudo, aumenta más rápidamente que los ejércitos y marinas a los que sirve; sus intereses y su poder limitan de modo considerable el carácter y la intensidad de la actividad bélica que cualquier Estado puede Ilevar a cabo" (Tilly, 1990: 46).

En la guerra interna, la población civil es involucrada con mayor intensidad. Es parte de la solución y del problema. Adicional a los tributos que se generan para costear el conflicto, la población es sometida a nuevas formas de legislaciones penales y de castigos. En muchos casos, la población es involucrada en los conflictos. El Estado incrementa medidas penales, con el objetivo de limitar o neutralizar no sólo el accionar militar, sino también restringir la protesta social. El castigo o la amenaza del castigo se convierte en un elemento estratégico de los Estados.

El fenómeno del castigo es un conjunto complejo de procesos e instituciones interrelacionados, más que un objeto o hecho uniforme ... se considera el castigo como el procedimiento legal que sanciona y condena a los transgresores del derecho penal, de acuerdo con categorías y procedimientos legales específicos. Este proceso, complejo y diferenciado, se conforma de procesos interrelacionados: legislación, condena y sentencia, así como administración de sanciones. Involucra marcos discursivos de autoridad y condena, procesos rituales de imposición del castigo, un repertorio de sanciones penales, instituciones y organismos para el cumplimiento de las sanciones y una retórica de 
símbolos, figuras e imágenes por medio de las cuales el proceso penal se representa ante los diversos estratos de la sociedad" (Garlan, 1999: 32-33).

En la mayoría de los casos, la legislación, la condena y las sentencias propuestas para enfrentar un conflicto armado interno terminan por desbordar Ios límites del Estado, violándose el Derecho Internacional Humanitario.

\section{LOS LÍMITES DE LAS LEGISLACIONES PENALES ESPECIALES}

En la mayoría de los casos, los Estados que aplican medidas de excepción generan efectos como otorgar prerrogativas a las Fuerzas Armadas para la lucha contra los actores armados. En segundo lugar, se crean procedimientos, sanciones y condenas dirigidas a limitar el accionar de los grupos armados. En tercer lugar, se suspenden garantías constitucionales y limitan los derechos políticos y sociales. Por último, las legislaciones especiales afectan el desarrollo de las organizaciones sociales y movimientos sociales y pueden ser mecanismos de control social. La creación y aplicación de medidas de excepción afectan el régimen político democrático, ya que con ellas el ejecutivo concentra el poder $y$, como consecuencia, se debilita la institución parlamentaria y se limita la independencia del sistema judicial. Por esta razón, la aplicación de "estados de excepción" es cuestionada por las organizaciones internacionales de Derechos Humanos.

Los tratados internacionales de Derechos Humanos y los Estados democráticos de Occidente prevén la posibilidad de crear estatutos especiales, con el fin de superar situaciones que alteren el orden público. Sin embargo, para contrarrestar el efecto de concentración del poder y limitación de los derechos civiles y políticos, la legislación internacional en Derechos Humanos establece unos límites a los gobiernos que expiden estatutos especia- les, éstos están señalados en el Pacto de Derechos Civiles y Políticos y en la Convención Americana sobre los Derechos Humanos.

El Pacto Internacional de Derechos Civiles y Políticos adoptado y abierto a la firma, ratificación y adhesión por la Asamblea General de las Naciones Unidas en su resolución 2200 A (XXI), de 16 de diciembre de 1966, señala en el artículo $4^{\circ}$ que:

1. En situaciones excepcionales que pongan en peligro la vida de la nación y cuya existencia haya sido proclamada oficialmente, Ios Estados Partes en el presente Pacto podrán adoptar disposiciones que, en la medida estrictamente limitada a las exigencias de la situación, suspendan las obligaciones contraídas en virtud de este Pacto, siempre que tales disposiciones no sean incompatibles con las demás obligaciones que les impone el derecho internacional y no entrañen discriminación alguna fundada únicamente en motivos de raza, color, sexo, idioma, religión u origen social. 2. La disposición precedente no autoriza suspensión alguna de los artículos 6, 7, 8 (párrafos 1y 2), 11, 15, 16 y 18. 3. Todo Estado Parte en el presente Pacto que haga uso del derecho de suspensión deberá informar inmediatamente a los demás Estados Partes en el presente Pacto, por conducto del Secretario General de las Naciones Unidas, de las disposiciones cuya aplicación haya suspendido y de los motivos que hayan suscitado la suspensión. Se hará una nueva comunicación por el mismo conducto en la fecha en que se haya dado por terminada tal suspensión.

El Pacto Internacional de Derechos Civiles y Políticos permite que los Estados miembros, es Colombia, desarrollen medidas para superar situaciones de peligro, pero establece como límites: el deber de proteger el derecho a la vida; la obligación de que nadie pueda ser sometido a torturas ni a penas o tratos crueles, inhumanos o degradantes; se privilegia el principio de legali- 
dad, ya que nadie será condenado por actos u omisiones que en el momento de cometerse no fueran delictivos según el derecho nacional o internacional; por último, se protege la libertad de pensamiento.

Por otra parte, la Convención Americana sobre Ios Derechos Humanos o Pacto de San José de Costa Rica, suscrita en 1969 durante la Conferencia Especializada Interamericana sobre Derechos Humanos, señala en su artículo $27^{\circ}$ que:

Suspensión de Garantías 1. En caso de guerra, de peligro público o de otra emergencia que amenace la independencia o seguridad del Estado Parte, éste podrá adoptar disposiciones que, en la medida y por el tiempo estrictamente limitados a las exigencias de la situación, suspendan las obligaciones contraídas en virtud de esta Convención, siempre que tales disposiciones no sean incompatibles con las demás obligaciones que les impone el derecho internacional y no entrañen discriminación alguna fundada en motivos de raza, color, sexo, idioma, religión u origen social. 2. La disposición precedente no autoriza la suspensión de los derechos determinados en los siguientes artículos: 3 (derecho al reconocimiento de la personalidad jurídica); 4 (derecho a la vida); 5 (derecho a la integridad personal); 6 (prohibición de la esclavitud y servidumbre); 9 (principio de legalidad y de retroactividad); 12 (libertad de conciencia y de religión); 17 (protección a la familia); 18 (derecho al nombre); 19 (derechos del niño); 20 (derecho a la nacionalidad), y 23 (derechos políticos), ni de las garantías judiciales indispensables para la protección de tales derechos. 3. Todo Estado Parte que haga uso del derecho de suspensión deberá informar inmediatamente a los demás Estados Partes en la presente Convención, por conducto del Secretario General de la Organización de los Estados Americanos, de las disposiciones cuya aplicación haya suspendido, de los motivos que hayan suscitado la suspensión y de la fecha en que haya dado por terminada tal suspensión".

En este contexto, todas las instituciones democráticas deben ser fortalecidas con el objetivo de evitar situaciones de arbitrariedad por parte del ejecutivo y en especial de la fuerza pública. Nos interesa analizar en este momento el papel del juez y de la administración de justicia en su tarea de asegurar el cumplimiento de los derechos y garantías que se encuentran consagrados en la Constitución y en los acuerdos y tratados internacionales sobre derechos humanos, como los atrás señalados.

\section{DIVISIÓN DEL PODER: INDEPENDENCIA DE LOS JUECES}

En los países de América Latina, el régimen político se ha caracterizado por la concentración del poder en el ejecutivo frente al legislativo $y$ al judicial. Sin embargo, esta situación ha cambiado de alguna manera, ya que las reformas constitucionales promovidas durante la última década del siglo XX posibilitaron una real división de poderes. En este ámbito, la administración de justicia logró jugar un papel importante en el fortalecimiento de la democracia.

Luego de más de un siglo, donde el poder judicial ha sido en parte un apéndice de los poderes ejecutivos, hoy afronta quizá una de las reformas más profundas a favor de una mayor institucionali-zación y profesionalización que debe impactar en sus niveles de independencia (Burgos, 2004:8).

En diversos países de la Región se han fortalecido los niveles de independencia judicial. Lo anterior se presentó por la combinación de dos elementos: en primer lugar, se dio un fortalecimiento institucional y, en segundo lugar, el desarrollo de una jurisdicción constitucional y un 
mayor protagonismo del juez en temas de orden económico, social y político. En el ámbito institucional se presentaron importantes cambios, como la creación de Consejos de la Judicatura que da mayor autonomía a la administración de justicia en el manejo del presupuesto y de la carrera judicial. El desarrollo constitucional se caracterizó por el aumentó de derechos políticos, económicos, sociales y culturales y de mecanismos para su exigibilidad y la creación de instituciones que garantizan la defensa de los Derechos Humanos de la población. Por último, el papel del juez como actor fundamental en la defensa y el cumplimiento de la Constitución considerada como norma jurídica lo convierte en agente protagonista de la sociedad.

Un mayor grado de independencia de la administración de justicia ha fortalecido los regímenes democráticos de América Latina.

La independencia judicial tiene una connotación fundamentalmente negativa, relativa a la ausencia de indebidas injerencias en la labor de administrar justicia por parte de los poderes ejecutivo y legislativo, las partes de un proceso, los actores sociales u organismos vinculados a la administración de justicia... Su objetivo inmediato es permitir el imperio de la ley y su aplicación de manera imparcial a los casos concretos ...la defensa de la Constitución es el segundo objetivo normativo de la independencia judicial (Burgos, 2004:13).

Pese a la importancia del poder judicial para el fortalecimiento de un régimen democrático en varios países de América Latina, se han efectuado procesos de contrarreforma de la administración de justicia para favorecer los intereses del ejecutivo. Ejemplo de ello han sido la injerencia del ex presidente de Argentina Carlos Menem en el poder judicial, quien, con apoyo del legislativo, reformó la Corte Suprema aumentando el número de magistrados de cinco a nueve, con lo cual creó una mayoría a su favor. Un segundo ejemplo se dio bajo el gobierno de Alberto Fujimori en Perú, a partir del autogolpe de Estado en 1992, que permitió destituir a todos los magistrados de las altas cortes y nombrar de facto a un nuevo grupo de jueces (Skaar, 2044: 274. Landa, 2004: 293).

En el caso colombiano, la Constitución de 1991 dio las bases para el fortalecimiento del Estado democrático social y de derecho. En ella se ampliaron los derechos y garantías de los ciudadanos y de los grupos étnicos; se crearon importantes mecanismos de exigibilidad, como la tutela, las acciones populares y de cumplimiento, y el logró de mayor independencia de la administración de justicia. Sin embargo, estos avances están siendo sometidos a cuestionamiento por el gobierno de Álvaro Uribe Vélez, Ilamado "el gobierno de la seguridad democrática", siendo las propuestas de reforma que éste promueve retrocesos para la democracia colombiana como, la disminución del grado de independencia judicial mediante la supresión del Consejo de la Judicatura, recortes a las funciones de control de la Corte Constitucional sobre la legislación de excepción y restricciones a la acción de tutela.

\section{EL CASO COLOMBIANO: "LA SEGURIDAD DEMOCRÁTICA" Y LA INDEPENDENCIA JUDICIAL}

Colombia ha enfrentado constantes cuestionamientos de parte de la comunidad internacional por la aplicación de los estados de excepción y el incumplimiento de los pactos internacionales de Derechos Humanos. El hecho más sobresaliente de la historia del siglo XX fue el Decreto extraordinario número 1923 del 6 de septiembre de 1978 conocido como "Estatuto de Seguridad", promulgado durante el gobierno de Julio César Turbay Ayala (1978-1982), mediante el cual se tipificaron nuevos delitos, se aumentaron las pe- 
nas de otros y se sometió a particulares a juzgamiento por tribunales y cortes marciales. Diversas ONG de Derechos Humanos, como Amnistía Internacional, cuestionaron en su época dicho estatuto.

El "Estatuto de Seguridad" fue una medida aplicada en lo fundamental a dirigentes sociales, sindicalistas, académicos y estudiantes.

Dicha ley emanada del poder ejecutivo, colocaba a la Policía Judicial bajo la tutela militar y suspendía garantías ciudadanas del habeas corpus y de inviolabilidad del domicilio, amparando una serie de allanamientos militares a la residencia de cuanto intelectual tuvo el infortunio de simpatizar con los rebeldes, pues la disposición atribuyó al mando militar funciones de investigación, seguimiento y juicio de civiles por delitos de orden público... Bajo la legislación de emergencia de los años ochenta, cualquier opinión política quedaba bajo sospecha, y el disenso y la protesta social podían ser acusados de rebelión y asonada. Toda oposición podía ser condenada a la pena prevista en las disposiciones ordinarias, en búsqueda del unanimismo, destinadas a reprimir el motín y la insurgencia (Derechos Humanos en Colombia, 2004:15).

La Constitución de 1991 quiso poner límites a los estados de excepción o conmoción interior para evitar abusos del poder y violaciones de los Derechos Humanos. El artículo 213 de la actual carta política señala:

En caso de grave perturbación del orden público que atente de manera inminente contra la estabilidad institucional, la seguridad del Estado o la convivencia ciudadana, y que no pueda ser conjurada mediante el uso de las atribuciones ordinarias de las autoridades de Policía, el Presidente de la República, con la firma de todos los ministros, podrá declarar el estado de conmoción interior, en toda la República o parte de ella, por término no mayor de noventa días, prorrogable hasta por dos períodos iguales, el segundo de los cuales requiere concepto previo y favorable del Senado de la República.

Mediante tal declaración, el Gobierno tendrá las facultades estrictamente necesarias para conjurar las causas de la perturbación e impedir la extensión de sus efectos. Los decretos legislativos que dicte el Gobierno podrán suspender las leyes incompatibles con el estado de conmoción y dejarán de regir tan pronto como se declare restablecido el orden público. El Gobierno podrá prorrogar su vigencia hasta por noventa días más.

Dentro de los tres días siguientes a la declaratoria o prórroga del estado de conmoción, el Congreso se reunirá por derecho propio con la plenitud de sus atribuciones constitucionales y legales. El Presidente le pasará inmediatamente un informe sobre las razones que determinaron la declaración.

En ningún caso, los civiles podrán ser investigados o juzgados por la justicia penal militar.

Desde su creación en 1991 hasta la fecha, la figura de la conmoción interior ha sido utilizada en cinco oportunidades por diferentes motivos. El gobierno de César Gaviria la declaró en dos ocasiones, Decretos 1155/92 y 874 de 1994. El Presidente Ernesto Samper, la decretó en dos oportunidades. Por último, el actual mandatario, Álvaro Uribe Vélez, utilizó la institución en una ocasión, mediante el Decreto 1837 de 2002, para crear las "zonas de rehabilitación" dentro de su política de seguridad democrática. Las motivaciones de las dos conmociones de Gaviria fueron evitar la concesión de libertad a peligrosos delincuentes por la imposibilidad de la Fiscalía 
de cumplir con los términos procesales. Uno de los estados de conmoción decretado por el presidente Samper se justificó por el asesinato del dirigente conservador Álvaro Gómez Hurtado, crimen que hasta la fecha permanece impune.

Durante los cuatro años del Gobierno de Andrés Pastrana (1998-2002) no se expidió ningún decreto de conmoción interior. En este gobierno se intentó un proceso de negociación con el principal grupo guerrillero del país, las Fuerzas Armadas Revolucionarias de Colombia, FARC-EP. Al finalizar dicho gobierno, los resultados del proceso fueron extremadamente negativos con respecto al objetivo de alcanzar la paz. En el contexto del fracaso del proyecto de negociación política con la guerrilla, fue elegido Álvaro Uribe Vélez como presidente de la república para el período 2002-2006, quien en su campaña desarrolló un discurso de "guerra total" contra la subversión.

Desde los primeros días de su gobierno, el presidente Álvaro Uribe Vélez implementó medidas de excepción con el objetivo de enfrentar la situación de orden público y fortalecer la seguridad democrática. En tal sentido, decretó la conmoción interior mediante Decreto Legislativo 1837 de 2002, prorrogando en dos ocasiones su vigencia mediante los Decretos 2555 de 2002 y 245 de 2003. En este escenario de excepción se expidieron normas que limitaron las libertades individuales; se impulsó la modificación del sistema penal y se afecto el presupuesto nacional con destino al financiamiento de la guerra. Cada uno de estos decretos llegó a conocimiento de la Corte Constitucional, lo mismo que las medidas adoptadas a su amparo, algunas de las cuales, como las Ilamadas "zonas de rehabilitación", no obtuvieron el paso de constitucionalidad (Sent. C-327-2003).

La propuesta posterior del gobierno fue convertir en permanente algunos de los mecanismos contemplados en los decretos de conmoción interior, para lo cual se impulsó una reforma constitucional que se materializó en el Acto Legislativo 02 de 2003 y 03 de 2003. El primero de los actos legislativos reformó importantes artículos de la Constitución con el fin de "enfrentar el terrorismo". Con fundamento en estas modificaciones a la Carta, se limitaron derechos básicos de un Estado democrático, como los derechos a la intimidad, a la libertad de movilización, al habeas corpus y se otorgaron funciones de policía judicial a las Fuerzas Armadas.

En este contexto, es indispensable, por parte de los actores democráticos, continuar la lucha por el fortalecimiento de los principios del Estado de derecho, como el de la división de poderes como mecanismo institucional para evitar caer en el autoritarismo. En segundo lugar, se hace necesario defender la independencia de jueces y fiscales. En la historia reciente del país, la administración de justicia ha jugado un papel importante en el fortalecimiento de la democracia, en especial gracias al papel jugado por el juez constitucional, que en más de una ocasión ha salido al paso a los desbordamientos y excesos del ejecutivo.

Dentro de este panorama, merecería un análisis particular la Fiscalía General de la Nación, que adolece de una excesiva centralización en cabeza del Fiscal General de la Nación que, unida a la inexistencia de una carrera judicial, plantea graves interrogantes a la vigencia de la independencia judicial de los funcionarios subalternos.

\section{CONCLUSIÓN}

El objetivo de este trabajo ha sido aportar un marco teórico y conceptual que permita establecer, de manera crítica, los límites de un Estado democrático cuando es confrontado por un actor armado. Si bien es cierto que en un contexto de guerra, el Estado tiene la obligación de de- 
fender la institucionalidad, las medidas que se tomen no pueden exceder los tratados internacionales de Derechos Humanos. Todo lo contrario, es necesario reafirmarse en los marcos internacionales y en las garantías constitucionales, así como fortalecer las instituciones democráticas, en particular la administración de justicia.

La situación actual del país comienza a preocupar a la comunidad internacional; si bien es cierto que con la Constitución de 1991 se fortaleció el Estado democratico, existen signos y propuestas gubernamentales que plantean una marcha atrás, como lo significó el "Estatuto Antiterrorista" declarado inconstitucional por la Corte Constitucional por vicios de trámite, las capturas masivas en muchas regiones del país, la reforma penal con el tránsito al sistema acusatorio sin una garantía efectiva del derecho de defensa para los sectores más pobres de la población, los anuncios de una reforma a la administración de justicia que pretende suprimir muchas de las conquistas democráticas de la Constiticón de 1991. La duda central seguirá siendo si, con todo ello, el Estado colombiano podrá recuperar la iniciativa en la lucha de la guerra interna, pero al precio de sacrificar la legitimidad que le había otorgado nuevo estatuto fundamental.

\section{BIBLIOGRAFÍA}

BURGOS, Germán. “¿Qué se entiende hoy por independencia judicial? Algunos elementos conceptuales". En: Independencia judicial en América Latina ¿de quién?, ¿para qué?, ¿cómo? Bogotá: Ilsa, 2004.

COMITÉ PERMANENTE POR LA DEFENSA DE LOS DERECHOS HUMANOS. Derechos Humanos en Colombia, Veinticinco Años. Bogotá, 2004.

GARLAND, David. Castigo y sociedad moderna: un estudio de teoría social. Mexico: Siglo Veintiuno Editores, Mexico, 1999.
HOBSBAWM, Erick. Historia del siglo XX. Barcelona: Editorial Crítica, 1997

HOWARD, Michael y W. Roger Louis. "Historia de Oxford del siglo XX". Madrid: Editorial Planeta, 1999.

KALDOR, Mary. Las nuevas guerras: la violencia organizada en la era global. Barcelona: Kriterios Tusquest, 2001.

LANDA, Cesra. "Balance de la reforma judicial del Perú a la luz de los derechos fundementales". En: Independencia judicial en América Latina ide quién?, ¿para qué?, ¿cómo? Bogotá: Ilsa, 2004.

TILLY, Charles. Coerción, capital y los Estados europeos 990-1990. Madrid: Alianza Editorial, 1990.

PNUD, "Orígenes: guerra en la periferia". En: EI conflicto: callejón con salida. Bogotá, 2003.

COLOMBIA, PROCURADURÍA GENERAL DE LA NACIÓN. Procuraduría General de la Nación y Estados de Excepción, Bogotá, 2004.

SKAAR, Elin.“Independencia judicial y política de derechos humanos en Argentina y Chile". En: Independencia Judicial en América Latina ¿de quién?, ¿para qué?, ¿cómo? Bogotá: Ilsa, 2004.

WILLS, María Emma. "En contra de la marea o cómo las violencias, a veces, producen democracia". En: Revista de estudios sociales, n. 1. Bogotá: Universidad de Los Andes, 1998.

\section{PACTOS INTERNACIONALES}

Convención Americana sobre los Derechos Humanos suscrita en 1969 durante la Conferencia Especializada Interamericana sobre Derechos Humanos.

Pacto Internacional de Derechos Civiles y Políticos, Naciones Unidas, 1966. 